\title{
The combination of sugammadex and neostigmine can reduce the dosage of sugammadex during recovery from the moderate neuromuscular blockade
}

\author{
Soon Ho Cheong, Seunghee Ki, Jiyong Lee, Jeong Han Lee, \\ Myoung-Hun Kim, Dongki Hur, Kwangrae Cho, Se Hun Lim, \\ Kun Moo Lee, Young-Jae Kim, and Wonjin Lee \\ Department of Anesthesiology and Pain Medicine, Busan Paik Hospital, Inje University College of Medicine, Busan, Korea
}

\begin{abstract}
Background: Sugammadex is a novel neuromuscular reversal agent, but its associated hypersensitivity reaction and high cost have been obstacles to its widespread use. In the interest of reducing the necessary dosage of sugammadex, the reversal time of the combined use of sugammadex and neostigmine from moderate neuromuscular blockade were investigated. Methods: The patients enrolled ranged in age from 18 to 65 years old with American Society of Anesthesiologists class 1 or 2. The subjects were randomly assigned into one of the four groups (Group S2, S1, SN, and N; $\mathrm{n}=30$ per group). The reversal agents of each groups were as follows: S2 - sugammadex $2 \mathrm{mg} / \mathrm{kg}$, S1 - sugammadex $1 \mathrm{mg} / \mathrm{kg}$, SN - sugammadex $1 \mathrm{mg} / \mathrm{kg}+$ neostigmine $50 \mu \mathrm{g} / \mathrm{kg}+$ glycopyrrolate $10 \mu \mathrm{g} / \mathrm{kg}, \mathrm{N}$ - neostigmine $50 \mu \mathrm{g} / \mathrm{kg}+$ glycopyrrolate $10 \mu \mathrm{g} / \mathrm{kg}$. The time to recovery of the train-of-four (TOF) ratio was checked in each group.

Results: The time to $90 \%$ recovery of TOF ratio was $182.6 \pm 88.9,371.1 \pm 210.4,204.3 \pm 103.2,953.2 \pm 379.7$ sec in group S2, S1, SN and N, respectively. Group SN showed a significantly shorter recovery time than did group S1 and N $(\mathrm{P}<0.001)$. However, statistically significant differences between the S2 and SN groups were not be observed $(\mathrm{P}=0.291)$. No hypersensitivity reactions occurred in all groups.

Conclusions: For the reversal from rocuronium-induced moderate neuromuscular blockade, the combined use of sugammadex and neostigmine may be helpful to decrease the recovery time and can also reduce the required dosage of sugammadex. However, the increased incidence of systemic muscarinic side effects must be considered.
\end{abstract}

Key Words: Neostigmine, Neuromuscular blockade, Rocuronium, Sugammadex.

Corresponding author: Wonjin Lee, M.D.

Department of Anesthesiology and Pain Medicine, Busan Paik Hospital, Inje University College of Medicine, 75, Bokji-ro, Busanjingu, Busan 47392, Korea

Tel: 82-51-890-6520, Fax: 82-51-898-4216

E-mail: 2wonjin@hanmail.net

Received: June 9, 2015.

Revised: 1st, July 1, 2015; 2nd, July 29, 2015.

Accepted: August 10, 2015.

Korean J Anesthesiol 2015 December 68(6): 547-555 http://dx.doi.org/10.4097/kjae.2015.68.6.547

\section{Introduction}

Sugammadex is a novel agent for the reversal of neuromuscular blockade, which functions by forming complexes in a $1: 1$ ratio with steroidal neuromuscular blocking agents. In contrast with anticholinesterases and other classic neuromuscular reversal agents, sugammadex has shown little to no cholinergic side effects and residual muscle relaxation [1-7]. Above all, the greatest advantage of sugammadex was ultra-rapid reversal from neuromuscular blockade, regardless of the degree of neuromus-

(c) This is an open-access article distributed under the terms of the Creative Commons Attribution Non-Commercial License (http://creativecommons.org/ licenses/by-nc/4.0/), which permits unrestricted non-commercial use, distribution, and reproduction in any medium, provided the original work is properly cited. 
cular blockade. Thus, sugammadex its clinical use has gained great interest [1-7]. However it has yet to be approved by the Food and Drug Administration of the USA (US FDA) due to the associated hypersensitivity reaction [8], and several previous studies have shown that the hypersensitivity reaction occurred more frequently at higher doses [9-12]. In addition, given that the price of sugammadex is much more expensive than classic neuromuscular reversal drugs, many anesthesiologists have been reluctant to use sugammadex in the interest of limiting health care spending costs $[6,13,14]$.

To reduce the dosage and overall cost of sugammadex, the combined use of sugammadex and neostigmine has been attempted. In a previous study, the combined use of sugammadex $0.5 \mathrm{mg} / \mathrm{kg}$ and neostigmine $40 \mu \mathrm{g} / \mathrm{kg}$ showed shorter time to reversal from deep neuromuscular blockade than did sugammadex $1 \mathrm{mg} / \mathrm{kg}$ alone [14]. The investigators in this study, however, used sub-clinical dosages of sugammadex despite deep neuromuscular blockade, and, thus, these results are difficult to apply in the clinically. In addition, as many surgeries are performed with moderate neuromuscular blockade $[15,16]$, we aimed to investigate recovery time from moderate neuromuscular blockade. Our pilot study to determine the dosage of sugammadex and neostigmine showed that the time to $90 \%$ recovery of trainof-four (TOF) ratio from moderate neuromuscular blockade (TOF count 1 or 2 ) was not significantly different between the combination of sugammadex $1 \mathrm{mg} / \mathrm{kg}$ and neostigmine $50 \mu \mathrm{g} /$ $\mathrm{kg}$ group and sugammadex $2 \mathrm{mg} / \mathrm{kg}$ group (144 \pm 15.8 vs. $125 \pm$ $16.2 \mathrm{sec})$.

We generated the hypothesis that the combination of sugammadex $1 \mathrm{mg} / \mathrm{kg}$ and neostigmine $50 \mu \mathrm{g} / \mathrm{kg}$ was not inferior to sugammadex $2 \mathrm{mg}$ alone in the time to recovery of TOF ratio from moderate neuromuscular blockade. We planned to compare the time to recovery of TOF ratio from moderate neuromuscular blockade between the use of sugammadex alone versus the combined use of sugammadex and neostigmine. In addition, the incidence of hypersensitivity reactions and systemic muscarinic side effects of each reversal agents were evaluated.

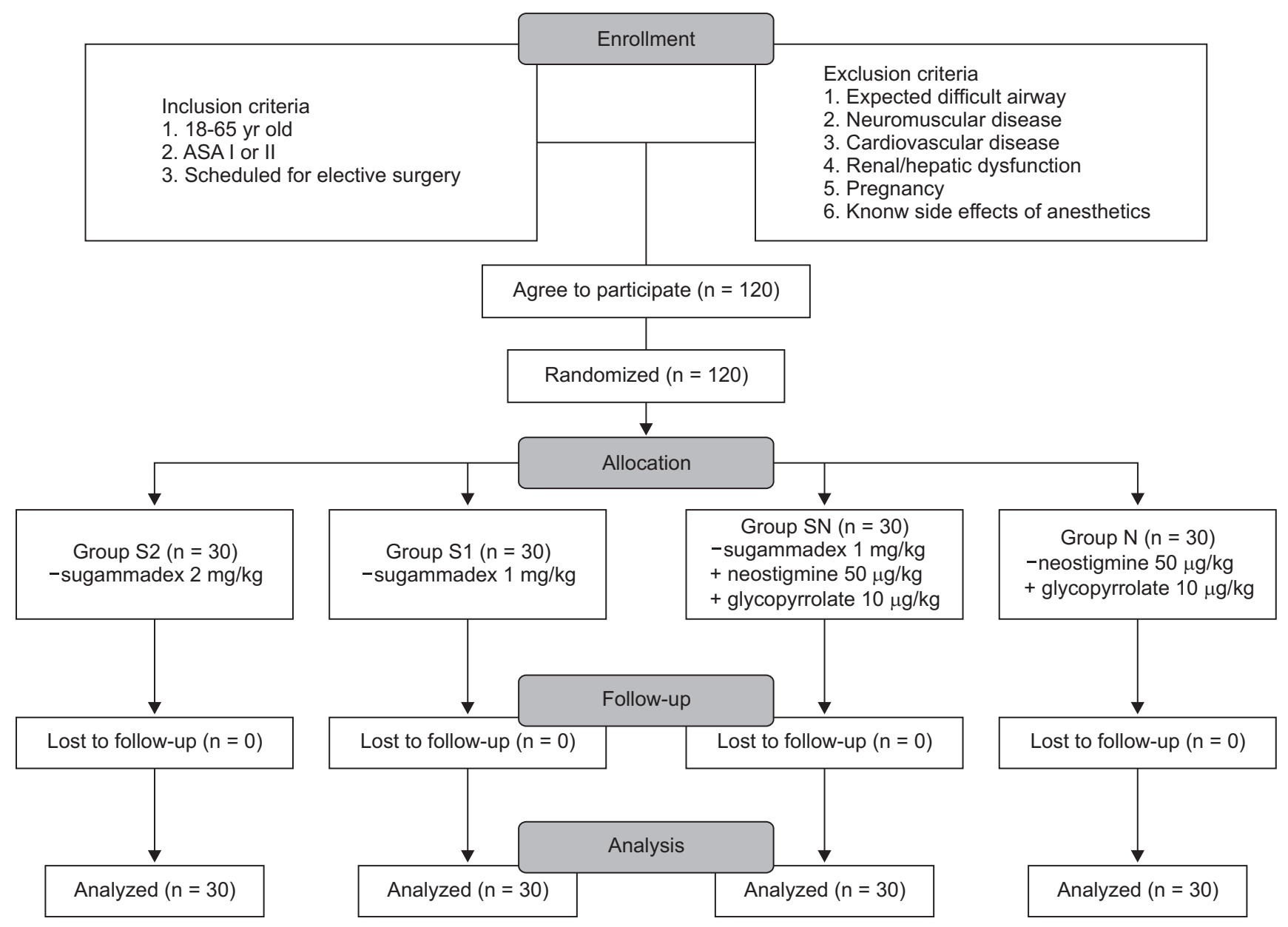

Fig. 1. CONSORT flow diagram. 


\section{Materials and Methods}

The present study was approved by our university Institutional Review Board. Written consent was obtained from all subjects who agreed to be involved in this study.

The 120 subjects were enrolled through the CONSORT process, as illustrated in Fig. 1. The inclusion criteria were age between 18 to 65 year olds; 1 or 2 American Society of Anesthesiologists (ASA) physical status; and scheduled for elective surgery in our hospital. The exclusion criteria were patients expected to have difficult intubation due to anatomical abnormality or limited neck mobility at preoperative evaluation; patients with neuromuscular abnormality; cardiovascular disease; kidney function disorder; liver function disorder; pregnancy; and history of side effects with anesthetics and analgesics. Experiment withdrawal criteria were unexpected massive hemorrhage; unrecovered electrocardiograph (ECG) abnormality; profound hypotension; respiratory abnormality; and TOF device error during experiment.

In the pilot study, we recorded the time to $90 \%$ recovery of TOF ratio in two group. The first group $(n=5)$ received intravenously administrated sugammadex $2 \mathrm{mg} / \mathrm{kg}$ alone, and the second group $(\mathrm{n}=5)$ received sugammadex $1 \mathrm{mg} / \mathrm{kg}$ and neostigmine $50 \mu \mathrm{g} / \mathrm{kg}+$ glycopyrrolate $10 \mu \mathrm{g} / \mathrm{kg}$. The time to $90 \%$ recovery of TOF ratio were $125 \pm 16.2 \mathrm{sec}$ in first group and $144 \pm 15.8 \mathrm{sec}$ in second group. Under the presumption that the difference of the time to $90 \%$ recovery of TOF ratio between groups was not more than $30 \mathrm{sec}$, the calculated sample size with alpha value 0.05 and power value $80 \%$ was 26 in each group. Considering $10 \%$ of the rate loss, the final sample size was determined to be 30 in each group.

The subjects were randomly assigned into one of four groups (Group S2, S1, SN and N). The Group S2 received sugammadex $2 \mathrm{mg} / \mathrm{kg}$ intravenously, group S1 received sugammadex $1 \mathrm{mg} / \mathrm{kg}$, group SN received sugammadex $1 \mathrm{mg} / \mathrm{kg}$ and neostigmine 50 $\mu \mathrm{g} / \mathrm{kg}+$ glycopyrrolate $10 \mu \mathrm{g} / \mathrm{kg}$, and group $\mathrm{N}$ received neostigmine $50 \mu \mathrm{g} / \mathrm{kg}+$ glycopyrrolate $10 \mu \mathrm{g} / \mathrm{kg}$ for reversal of neuromuscular blockade. To minimize observer bias, the drugs were prepared in syringes labelled "reverse" by a third party. When bradycardia (heart rate; HR $<50$ beats/min) or hypotension (mean blood pressure; MBP $<60 \mathrm{mmHg}$ ) occurred, atropine 0.5 $\mathrm{mg}$ or ephedrine $5 \mathrm{mg}$ were administered.

All patients were received glycopyrrolate $4 \mu \mathrm{g} / \mathrm{kg}$ intramuscularly for premedication 30 minutes before the operation. After the subjects entered the operating room, the ECG, blood pressure (BP), and pulse oximetry were monitored and two stimulating electrodes of TOF-Watch ${ }^{\circledR}$ (NV Organon, OSS, The Netherlands) were attached over the ulnar nerve on the wrist at intervals of 3 to $4 \mathrm{~cm}$ and the accelerometer was fixed on the ipsilateral thumb. Anesthesia was induced with intravenous propofol $1.5-2.5 \mathrm{mg} / \mathrm{kg}$ and rocuronium $0.6 \mathrm{mg} / \mathrm{kg}$, and maintained with sevoflurane $1.5-2.5$ vol $\%$ and $50 \% \mathrm{~N}_{2} \mathrm{O}$. During the operation, end tidal $\mathrm{CO}_{2}$ was maintained at $30-35 \mathrm{mmHg}$ and axillary temperature was maintained $35.0-37.5^{\circ} \mathrm{C}$. TOF count was monitored with $50 \mathrm{~mA}$ current, at 15 min intervals, and rocuronium 5-10 mg was administered intermittently to maintain TOF count under 2.

Following the operation, the anesthesiologist waited till the TOF count was 1 or 2 , then the reversal agent of each group was administered. During the neuromuscular recovery period, the end-expiratory concentration of sevoflurane, displayed on the Primus anesthetic workstation (Dräger, Lübeck, Germany), was maintained to 1 minimal alveolar concentration. The TOF was checked every $15 \mathrm{sec}$ till the TOF ratio reached $90 \%$, and the time to 70,80 and $90 \%$ recovery of TOF ratio were also recorded. In addition, the $\mathrm{HR}$ and $\mathrm{BP}$ were checked when the reversal drug was administered as well as 2, 5, 10 min thereafter. The presence or absence of a hypersensitivity reaction, including manifestations such as skin rash, hypotension, tachycardia and decreased $\mathrm{SpO}_{2}$ were recorded after administration of sugammadex. When the TOF ratio surpassed 90\%, sevoflurane was discontinued and fentanyl $0.5 \mu \mathrm{g} / \mathrm{kg}$ and ramosetron $5 \mu \mathrm{g} / \mathrm{kg}$ were subsequently administered intravenously to control postoperative pain and nausea / vomiting (PONV).

At the post-anesthesia care unit, PONV score $(0=$ no nausea or vomiting, 1 = nausea but no vomiting, 2 = vomiting, $3=$ persistent vomiting despite of additional therapy) and signs of residual neuromuscular blockade (removing the tongue after manual grasping, and maintaining head up for 5 seconds) were checked. Subsequently, BP and oxygen saturation were monitored for 30 minutes until the subjects returned to the wards. Before subjects went to the wards, patients were examined for signs of residual neuromuscular blockade once more.

All measured data are shown as mean \pm standard deviation (SD). Differences of ASA physical status and PONV score among groups were analyzed using chi-square test or Fisher's exact test. The other continuous parameters were analyzed using the Kolmogorov-Smironov test. The normally distributed data were analyzed using ANOVA and a post-hoc analysis was performed by Tukey's HSD analysis. If the data did not follow a normal distribution, the Kruskal-Wallis test and Mann-Whitney U-test were used. The statistical analyses was conducted using SPSS version 18 (SPSS Inc., Chicago, IL, USA) and P value below 0.05 was assumed to be statistically significant.

\section{Results}

The age and body weight (BW) were normally distributed and the other values did not follow normal distribution. Baseline characteristics are shown in Table 1 . The BW of the groups 
Table 1. Baseline Characteristics

\begin{tabular}{lcccc}
\hline & Group S2 & Group S1 & Group SN & Group N \\
\hline Number (person) & 30 & 30 & 30 & 30 \\
Sex (M/F) & $17 / 13$ & $16 / 14$ & $17 / 13$ & $8 / 22$ \\
Age (yr) & $44.7 \pm 15.2$ & $52.5 \pm 15.3$ & $45.1 \pm 13.7$ & $46.9 \pm 12.2$ \\
Weight (kg) & $61.2 \pm 10.3$ & $67.9 \pm 11.3$ & $63.0 \pm 11.1$ & $60.6 \pm 8.9$ \\
Height (cm) & $164.0 \pm 7.6$ & $164.6 \pm 9.1$ & $163.4 \pm 9.0$ & $162.1 \pm 6.6$ \\
ASA (I/II) & $18 / 12$ & $17 / 13$ & $21 / 9$ & $19 / 11$ \\
Type of Operation & 18 & 13 & & 15 \\
$\quad$ Face or neck surgery & 5 & 6 & 6 & 4 \\
Laparoscopic surgery & 5 & 6 & 7 & 6 \\
Laparotomy surgery & 2 & 5 & 2 & 3 \\
Surgery of extremities & & & \\
\hline
\end{tabular}

Values are expressed as number or mean \pm standard deviation. Group S2: sugammadex $2 \mathrm{mg} / \mathrm{kg}$, Group S1: sugammadex $1 \mathrm{mg} / \mathrm{kg}$, Group SN: sugammadex $1 \mathrm{mg} / \mathrm{kg}+$ neostigmine $50 \mu \mathrm{g} / \mathrm{kg}$ + glycopyrrolate $10 \mu \mathrm{g} / \mathrm{kg}$, Group N: neostigmine $50 \mu \mathrm{g} / \mathrm{kg}+$ glycopyrrolate $10 \mu \mathrm{g} / \mathrm{kg}$. ASA: American Society of Anesthesiologists physical status.

Table 2. The Time to Recovery of TOF Ratio (sec)

\begin{tabular}{|c|c|c|c|c|c|}
\hline \multirow{2}{*}{ TOF ratio } & \multicolumn{4}{|c|}{ Group } & \multirow{2}{*}{$P$ value } \\
\hline & S2 & S1 & SN & $\mathrm{N}$ & \\
\hline $70 \%$ & $\begin{array}{c}113.2 \pm 55.3^{*, \dagger} \\
(92.5-133.8)\end{array}$ & $\begin{array}{c}225.5 \pm 156.2^{*} \\
(167.2-283.8)\end{array}$ & $\begin{array}{c}130.7 \pm 67.1^{*, \neq} \\
(105.7-155.8)\end{array}$ & $\begin{array}{l}635.5 \pm 317.0^{\dagger} \\
(517.2-753.9)\end{array}$ & $<0.001$ \\
\hline $80 \%$ & $\begin{array}{c}144.8 \pm 69.5^{*,+} \\
(118.8-170.7)\end{array}$ & $\begin{array}{c}286.7 \pm 167.3^{*} \\
(224.2-349.2)\end{array}$ & $\begin{array}{c}168.3 \pm 94.5^{*,+} \\
(133.1-203.7)\end{array}$ & $\begin{array}{c}793.3 \pm 350.5^{\dagger} \\
(662.5-924.3)\end{array}$ & $<0.001$ \\
\hline $90 \%$ & $\begin{array}{c}179.2 \pm 88.3^{*, \dagger} \\
(146.2-212.2)\end{array}$ & $\begin{array}{c}371.1 \pm 210.5^{*} \\
(292.5-449.7)\end{array}$ & $\begin{array}{c}204.3 \pm 103.3^{*, \dagger} \\
(165.7-242.9)\end{array}$ & $\begin{array}{c}953.2 \pm 379.8^{\dagger} \\
(811.4-1,095.0)\end{array}$ & $<0.001$ \\
\hline
\end{tabular}

Values are expressed as mean \pm standard deviation (95\% confidence interval). Group S2: sugammadex $2 \mathrm{mg} / \mathrm{kg}$, Group S1: sugammadex $1 \mathrm{mg} / \mathrm{kg}$, Group SN: sugammadex $1 \mathrm{mg} / \mathrm{kg}+$ neostigmine $50 \mu \mathrm{g} / \mathrm{kg}+$ glycopyrrolate $10 \mu \mathrm{g} / \mathrm{kg}$, Group N: neostigmine $50 \mu \mathrm{g} / \mathrm{kg}+$ glycopyrrolate $10 \mu \mathrm{g} / \mathrm{kg}(* \mathrm{P}<$ 0.001 when compared with group $\mathrm{N},{ }^{\dagger} \mathrm{P}<0.001$ when compared with group $\mathrm{S} 1,{ }^{7} \mathrm{P}<0.05$ when compared with group S1).

$\mathrm{S} 1$ and $\mathrm{N}$ showed statistically significant differences $(\mathrm{P}=0.035)$, and the other values did not showed significant differences between each group.

\section{TOF recovery time}

The times to recovery of TOF ratio are shown in Table 2 and Fig. 2. The time to 70,80 , and $90 \%$ recovery of TOF ratio were not statistically significantly different between groups S2 and SN ( $\mathrm{P}$ values were 0.368 in 70\%, 0.456 in 80\%, 0.291 in 90\%). Group $\mathrm{N}$ showed statistically significant differences to the other groups $(\mathrm{P}<0.001)$, however group $\mathrm{S} 1$ showed statistically significant difference to the $\mathrm{SN}(\mathrm{P}=0.001$ in $70 \%, \mathrm{P}<0.001$ in $80 \%$ and $90 \%)$ and $\mathrm{S} 2$ groups $(\mathrm{P}<0.001)$.

\section{Incidence of adverse effect}

The MBP and HR after the administration of the reversal agents are shown in Table 3 and Fig. 3. Immediately following administration of the reversal agents, the MBP of group SN was significantly lower than that of group S2 and N ( $\mathrm{P}=0.013$ and 0.027 , respectively). After $5 \mathrm{~min}$ of the reversal agent adminis-

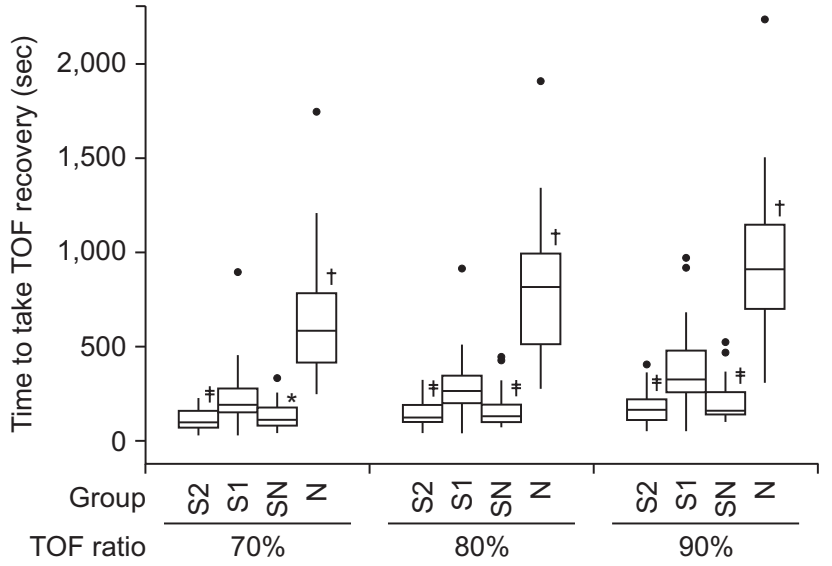

Fig. 2. The time to 70,80 and $90 \%$ recovery of TOF ratio. Group N showed significantly longer time to 70,80 and $90 \%$ recovery of TOF ratio than the other groups $(\mathrm{P}<0.001)$. Group S2 and Group SN did not show significant difference in time to 70,80 and $90 \%$ recovery of TOF ratio. The thick lines represent the median values, boxes indicate the interquartile range, whiskers represent the $10^{\text {th }}$ and $90^{\text {th }}$ percentiles, and block dots represent outliers. Group S2: sugammadex $2 \mathrm{mg} / \mathrm{kg}$, Group S1: sugammadex $1 \mathrm{mg} / \mathrm{kg}$, Group SN: sugammadex $1 \mathrm{mg} / \mathrm{kg}+$ neostigmine $50 \mu \mathrm{g} / \mathrm{kg}+$ glycopyrrolate $10 \mu \mathrm{g} / \mathrm{kg}$, Group N: neostigmine $50 \mu \mathrm{g} / \mathrm{kg}+$ glycopyrrolate $10 \mu \mathrm{g} / \mathrm{kg}(* \mathrm{P}<0.05$ when compared with group $\mathrm{S} 1,{ }^{\dagger} \mathrm{P}<0.001$ when compared with the other groups, ${ }^{\dagger} \mathrm{P}<0.001$ when compared with group S1). 
Table 3. The Mean Blood Pressure (MBP) and Heart Rate (HR) after Administration of Reversal Agents

\begin{tabular}{|c|c|c|c|c|c|c|}
\hline \multirow{2}{*}{\multicolumn{2}{|c|}{$\begin{array}{c}\text { Time after reverse } \\
(\mathrm{min})\end{array}$}} & \multicolumn{4}{|c|}{ Group } & \multirow{3}{*}{$\begin{array}{r}\text { P value } \\
0.049\end{array}$} \\
\hline & & \multirow{2}{*}{$\frac{\text { S2 }}{77.9 \pm 12.7^{*}}$} & \multirow{2}{*}{$\frac{S 1}{74.6 \pm 11.6}$} & \multirow{2}{*}{$\frac{\mathrm{SN}}{70.1 \pm 10.3^{\dagger}}$} & \multirow{2}{*}{$\frac{\mathrm{N}}{76.2 \pm 11.4^{*}}$} & \\
\hline $\mathrm{MBP}(\mathrm{mmHg})$ & 0 & & & & & \\
\hline & 2 & $77.8 \pm 14.2$ & $77.8 \pm 13.3$ & $74.5 \pm 12.6$ & $77.8 \pm 14.6$ & 0.641 \\
\hline & 5 & $79.1 \pm 13.7^{*}$ & $83.3 \pm 15.6^{*, \dagger}$ & $70.9 \pm 10.4$ & $72.4 \pm 13.9$ & 0.002 \\
\hline & 10 & $88.2 \pm 16.0^{\dagger}$ & $86.7 \pm 17.6^{\dagger}$ & $80.1 \pm 14.6$ & $75.3 \pm 13.1$ & 0.007 \\
\hline \multirow[t]{4}{*}{ HR (bpm) } & 0 & $75.4 \pm 11.8$ & $73.0 \pm 12.2$ & $71.3 \pm 12.0$ & $71.1 \pm 13.2$ & 0.354 \\
\hline & 2 & $70.5 \pm 11.3$ & $71.2 \pm 11.1$ & $73.3 \pm 11.3$ & $68.6 \pm 12.3$ & 0.251 \\
\hline & 5 & $71.3 \pm 12.7^{*, \neq}$ & $70.1 \pm 12.7^{*, \neq}$ & $61.5 \pm 10.9$ & $58.1 \pm 11.7$ & $<0.001$ \\
\hline & 10 & $78.2 \pm 12.7^{*, \neq}$ & $73.1 \pm 12.4^{\ddagger}$ & $69.2 \pm 17.8^{\dagger}$ & $56.5 \pm 10.3^{*}$ & $<0.001$ \\
\hline
\end{tabular}

Values are expressed as mean \pm standard deviation. Group S2: sugammadex $2 \mathrm{mg} / \mathrm{kg}$, Group S1: sugammadex $1 \mathrm{mg} / \mathrm{kg}$, Group SN: sugammadex 1 $\mathrm{mg} / \mathrm{kg}+$ neostigmine $50 \mu \mathrm{g} / \mathrm{kg}+$ glycopyrrolate $10 \mu \mathrm{g} / \mathrm{kg}$, Group N: neostigmine $50 \mu \mathrm{g} / \mathrm{kg}+$ glycopyrrolate $10 \mu \mathrm{g} / \mathrm{kg}\left({ }^{*} \mathrm{P}<0.05\right.$ when compared with group $\mathrm{SN},{ }^{\dagger} \mathrm{P}<0.05$ when compared with group $\mathrm{N},{ }^{\dagger} \mathrm{P}<0.001$ when compared with group $\mathrm{N}$ ).

A

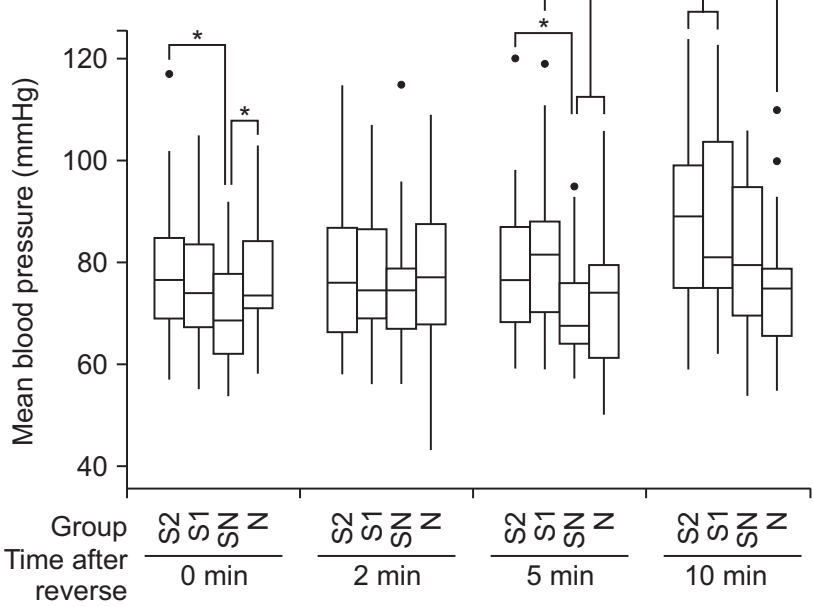

B

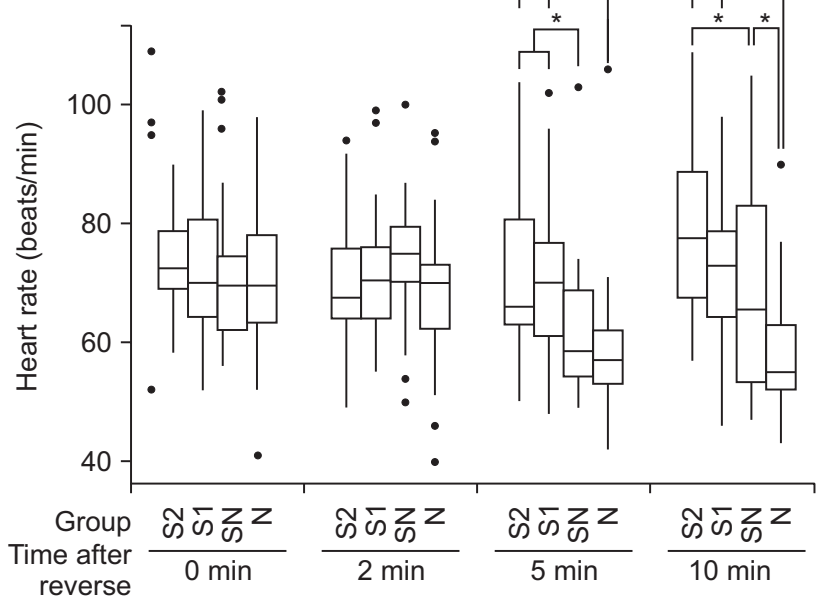

Fig. 3. The trend of the (A) mean blood pressure (MBP), and (B) heart rate (HR) after administration of neuromuscular reversal agents. (A) Immediately after the reversal agents administration, the MBP of group SN was significantly lower than group $\mathrm{S} 2$ and $\mathrm{N}(\mathrm{P}<0.05)$. After 5 min of the reversal agents administration, the MBP of the group SN and N were significantly lower than that of group S1 $(\mathrm{P}<0.05)$, and the MBP of group SN was significantly lower than that of S2 $(\mathrm{P}<0.05)$. After $10 \mathrm{~min}$ of the reversal agents administration, group $\mathrm{N}$ showed significantly lower MBP than group S2 and S1 $(\mathrm{P}<0.05)$. (B) The HR of the group N were significantly lower than group S1 and S2 after 5 and 10 min of the reversal agents administration $(\mathrm{P}<0.001)$. The group SN showed significantly lower HR than group S2 and S1 $(\mathrm{P}<0.05)$ after 5 min, and significantly higher HR than group N $(\mathrm{P}<0.05)$ and lower HR than group S2 $(\mathrm{P}<0.05)$ after 10 min of the reversal agents administration. The thick lines represent the median values, boxes indicate the interquartile range, whiskers represent the $10^{\text {th }}$ and $90^{\text {th }}$ percentiles, and block dots represent outliers. Group S2: sugammadex $2 \mathrm{mg} / \mathrm{kg}$, Group S1: sugammadex $1 \mathrm{mg} / \mathrm{kg}$, Group SN: sugammadex $1 \mathrm{mg} / \mathrm{kg}+$ neostigmine $50 \mu \mathrm{g} / \mathrm{kg}+$ glycopyrrolate $10 \mu \mathrm{g} / \mathrm{kg}$, Group N: neostigmine $50 \mu \mathrm{g} / \mathrm{kg}+$ glycopyrrolate $10 \mu \mathrm{g} / \mathrm{kg}\left({ }^{*} \mathrm{P}<0.05,{ }^{\dagger} \mathrm{P}<0.001\right.$ when compared between groups).

tration, the $\mathrm{MBP}$ of the group $\mathrm{SN}$ and $\mathrm{N}$ were significantly lower than that of the $\mathrm{S} 1$ group $(\mathrm{P}=0.001$ and 0.005 , respectively), and the MBP of the SN group was significantly lower than that of S2 $(\mathrm{P}=0.01)$. Ten min after administration of the reversal agents, the $\mathrm{N}$ group showed significantly lower MBP than did the S2 and $\mathrm{S} 1$ groups $(\mathrm{P}=0.002$ and 0.014 , respectively).

The HR of the SN group was significantly lower than that of $\mathrm{S} 2$ and $\mathrm{S} 1(\mathrm{P}=0.001$ and 0.002 , respectively), and the HR of the $\mathrm{N}$ group was also significantly lower that of group S2 and $\mathrm{S} 1(\mathrm{P}<0.001)$ after $5 \mathrm{~min}$ of the reversal agents administration.
After 10 min of the reversal agents administration, group $\mathrm{N}$ showed significant lower HR than groups S2, S1 $(\mathrm{P}<0.001)$, and $\mathrm{SN}(\mathrm{P}=0.007)$. The HR of group $\mathrm{SN}$ was significantly lower than that of group S2 $(\mathrm{P}=0.031) 10$ min following administration of the reversal agents. Bradycardia or hypotension was present in 3 patients in the SN group (10\%) and in 4 patients in group $\mathrm{N}(13 \%)$. After one time administration of atropine $0.5 \mathrm{mg}$ or ephedrine $5 \mathrm{mg}$ intravenously, BP and HR were normalized.

There were no patients with PONV score over 3 in the postanesthetic care unit in all groups. The number of patients with 
PONV score 2 were 1 (3.3\%), 1 (3.3\%), 2 (6.7\%), 4 (13.3\%) in group S2, S1, SN, N, respectively. Moreover, there were no signs of hypersensitivity reactions and residual neuromuscular blockade in all subjects.

\section{Discussion}

The present study demonstrates that the combined use of sugammadex $1 \mathrm{mg} / \mathrm{kg}$ and neostigmine $50 \mu \mathrm{g} / \mathrm{kg}$ shortened the time to $90 \%$ recovery of TOF ratio than that of sugammadex 1 $\mathrm{mg} / \mathrm{kg}$ alone in patients with moderate neuromuscular blockade. In addition, a statistically significant difference of the time to $90 \%$ recovery of TOF ratio could not be observed between the administration of sugammadex $2 \mathrm{mg} / \mathrm{kg}$ and the combined use of sugammadex $1 \mathrm{mg} / \mathrm{kg}$ and neostigmine $50 \mu \mathrm{g} / \mathrm{kg}$.

Anticholinesterases have been used most commonly for the reversal of neuromuscular blockade $[1,5]$. Anticholinesterase inhibits the breakdown of acetylcholine within the neuromuscular junction by reversibly attaching to acetylcholinesterase. Increased acetylcholine within the neuromuscular junction competes against non-depolarizing neuromuscular blocking agents and affects the nicotinic receptor in the motor end plate $[1,5]$. Anticholinesterase action can evoke systemic muscarinic side effects such as bradycardia, QT interval prolongation, PONV, an bronchial spasm, by affecting the branches of the autonomic nervous system that use acetylcholine as the neurotransmitter $[1,17,18]$. To reduce systemic muscarinic side effects of anticholinesterase activity, anticholinergic drugs such as atropine or glycopyrrolate are administrated with anticholinesterase. Since anticholinesterase cannot inactivate or break down neuromuscular blocking agents themselves, the residual neuromuscular blockade or recurarization by neuromuscular blocking agent can occur $[19,20]$. Therefore, respiratory complications such as atelectasis and pneumonia may occur in the recovery period, as can hypoxic brain damage in more severe cases [1,21-23].

Sugammadex is a recently-developed neuromuscular reversal agent that can overcome the limitations of anticholinesterase. Sugammadex has a modified $\gamma$-cyclodextrin structure that forms a complex in a $1: 1$ ratio with steroidal neuromuscular blocking agents, thereby inactivating the neuromuscular blocking agent. This mechanism enables fast reversal from neuromuscular blockade regardless of the depth of the neuromuscular blockade [1-4]. Moreover sugammadex is not associated with the systemic muscarinic side effects of anticholinesterase [1-4]. However, the hypersensitivity reaction has been a major obstacle to its widespread clinical application $[8,9,24,25]$. This adverse reactions occurs within 5 min of sugammadex administration and can be life-threatening, manifesting as skin rash, hypotension, tachycardia or decreased $\mathrm{SpO}_{2}[8,24,25]$. The hypersensitivity reaction was known to occur with first exposure of sugammadex, and it was hypothesized that patients were sensitized by the cyclodextrins present in food [8]. The dosage of sugammadex associated with hypersensitivity were 1.8 to $32.0 \mathrm{mg} / \mathrm{kg}[8,12,24,25]$, and it was thought to occur more frequently at higher doses [9-11]. Hypersensitivity reactions were not be observed in the present study. The incidence of hypersensitivity with sugammadex is not known, however it is considered to be low and to be dosedependent [9-11]. Since the number of subjects in the present study may be too small to observe hypersensitivity reaction, it is not clear if the absence of hypersensitivity in the present study was related to the low dosage of sugammadex. Moreover, the presumption that the hypersensitivity reaction of sugammadex occurs in a dose-dependent manner has yet to be verified, and more clinical experience with large-scale studies may be needed. However reducing the dosage of sugammadex may be a viable alternative for the anesthesiologist who raises concern regarding the hypersensitivity reaction and higher costs associated with sugammadex. In the present study, sugammadex and neostigmine were combined, under the hypothesis that the neuromuscular reversal effect of sugammadex and neostigmine may be synergistic due to different neuromuscular reversal mechanisms. To test this hypothesis, the S1 and SN groups were compared. In addition, we investigated whether the combined use of sugammadex and neostigmine could reduce the dose requirements of sugammadex by comparing the $\mathrm{S} 2$ and $\mathrm{SN}$ group.

There have been several studies comparing sugammadex and neostigmine [13,17,18,26,27]. Blobner et al. [26] compared the neuromuscular reversal time from moderate muscle blockade of sugammadex and neostigmine. The time taken from TOF count 2 to TOF ratio $90 \%$ was $90 \mathrm{sec}$ in the group that received sugammadex $2 \mathrm{mg} / \mathrm{kg} ; 1,116 \mathrm{sec}$ in the group that received neostigmine $50 \mu \mathrm{g} / \mathrm{kg}$ and glycopyrrolate $10 \mu \mathrm{g} / \mathrm{kg}$ during anesthesia with sevoflurane. Kakinuma et al. [14] showed that the combined use of sugammadex and neostigmine was more effective than the use of sugammadex alone in the setting of profound neuromuscular blockade induced by rocuronium. In the present study, sugammadex $1 \mathrm{mg} / \mathrm{kg}$ were administered in the control group and sugammadex $0.5 \mathrm{mg} / \mathrm{kg}$ and neostigmine $40 \mu \mathrm{g} / \mathrm{kg}$ were administered in the experimental group $5 \mathrm{~min}$ after administration of rocuronium $0.6 \mathrm{mg} / \mathrm{kg}$. The times to $90 \%$ recovery of TOF ratio were $29.9 \pm 7.5 \mathrm{~min}$ in the control group and $18.8 \pm 8.9$ $\mathrm{min}$ in the experimental group. However the results of this study are difficult to extrapolate into clinical anesthesia, given that the dosage of sugammadex was too small despite profound neuromuscular blockade. The present study measured the recovery time from moderate neuromuscular blockade, in contrast with the previous study, given that most surgeries required moderate depth of neuromuscular blockade to an approximate TOF count 1-2 [15,16]. Moreover $2 \mathrm{mg} / \mathrm{kg}$ of sugammadex was used, which was the most effective dosage at moderate neuromuscular 
blockade $[1,2,4,5,27,28]$.

Neostigmine can cause systemic muscarinic side effects, such as bradycardia, hypotension, and PONV $[1,17,18]$. Geldner et al. [17] showed that the HR in the group that received neostigmine was lower than that of the group the group that received sugammadex. PONV, however, was affected by patients' risk factors rather than the kinds of drugs administered. Hovorka et al. [29] also showed that neostigmine has no effect on the incidence or severity of PONV. In the present study, to reduce the systemic muscarinic side effect, glycopyrrolate was administered with neostigmine. Nevertheless, the BP and HR of the neostigmine administered groups were lower than that of the sugammadex only groups, particularly at 5,10 min following the administration of the reversal agent (Fig. 3). Furthermore, bradycardia or hypotension occurred in groups that received neostigmine: $10 \%$ in the SN group, $13 \%$ in group N. Nonetheless, this was easily stabilized by administration of atropine or ephedrine once. To reduce PONV, ramosetron $5 \mu \mathrm{g} / \mathrm{kg}$ was also administered intravenously. The incidence of PONV in the post-anesthetic care unit was 3.3, 3.3, 6.7, 13.3\% in group S2, S, SN, N, respectively, and severe PONV (PONV score over 3 ) was not observed among all groups. However, it is not clear that neostigmine increased PONV, given that the number of subjects was too small to analyze the incidence of the PONV. Overall, the incidence of systemic muscarinic side effects, including bradycardia and hypotension, may be increased after neostigmine administration.

Many anesthesiologists agree that sugammadex is a very fascinating agent that has many advantages over anticholinesterase. However the relatively higher cost of sugammadex has been a constraint on its use $[6,13,14]$. The approximate costs of drugs are as follows (May 2015 in Korea):

Sugammadex (Bridion ${ }^{\circledR}$, MSD, Seoul, Korea): 142 USA dollar (USD) in $200 \mathrm{mg}$

Neostigmine (Daihan-neostigmine ${ }^{\circledR}$, Daihan Pharm, Seoul, Korea): 0.45 USD in $0.5 \mathrm{mg}$

Glycopyrrolate (Mobinul ${ }^{\circledR}$, Myungmoon Pharm, Seoul, Korea): 0.65 USD in $0.2 \mathrm{mg}$

The costs of reversal agents per BW $(\mathrm{kg})$ in each groups can be calculated as follows:

$$
\begin{aligned}
& \text { Group S2: }(142 \times 2 \times B W) / 200 \\
& \text { Group S1: }(142 \times 1 \times B W) / 200 \\
& \text { Group SN: }(142 \times 1 \times B W) / 200+(0.45 \times 0.05 \times B W) / \\
& \qquad 0.5+(0.65 \times 0.01 \times B W) / 0.2
\end{aligned}
$$

Group N: $(0.45 \times 0.05 \times B W) / 0.5+(0.65 \times 0.01 \times B W) / 0.2$

The opportunity cost in the operating theater was assumed $£ 4.44$ (about 7 USD) per min [13], and calculated using the following equation: $7 \times$ Time to $90 \%$ recovery of TOF ratio ( $\mathrm{min}$ ). The estimated total cost was defined as the sum of cost of reversal agents and the opportunity cost in the operating theater. The estimated total costs of each groups were 107.9 $\pm 17.1,91.5 \pm$
24.8, $73.5 \pm 13.9,115.9 \pm 44.2$ (95\% CI: 101.5-114.2, 82.3-100.8, 68.2-78.7, 99.4-132.4) USD in group S2, S1, SN, N, respectively. The estimated total cost of group S2 was not significantly different from that of group $\mathrm{N}(\mathrm{P}=0.665)$, and the estimated total cost of group SN was significantly lower than that of group S2 and $\mathrm{N}(\mathrm{P}<0.001)$. Group SN showed the fast recovery time, similar with that of group S2, with the lowest cost. Sugammadex was commercialized under the name of Bridion ${ }^{\circledR}$, and it contained $200 \mathrm{mg}$ per ampule. One ampule is enough to reverse moderate neuromuscular blockade by administering $2 \mathrm{mg} / \mathrm{kg}$, if the patient's weight is under $100 \mathrm{~kg}$. Therefore the drug cost calculation of the present study may not be coincident with the actual cost. However, if a sugammadex ampule of under $200 \mathrm{mg}$ is released, overall costs may be reduced by combined use of sugammadex and neostigmine.

The combination of sugammadex and neostigmine has its advantages and disadvantages. Given the dosage and cost, the combination of sugammadex $1 \mathrm{mg} / \mathrm{kg}$ and neostigmine $50 \mu \mathrm{g} /$ $\mathrm{kg}$ can replace the sugammadex $2 \mathrm{mg} / \mathrm{kg}$ alone. However the incidence of systemic muscarinic side effects, such as bradycardia, hypotension, and PONV may be increased with neostigmine administration. Although the side effects were not serious and easily controlled in the present study, the use of sugammadex alone may be beneficial if the higher cost and increased probability of hypersensitivity are not considered.

The present study has several limitations. Firstly, the BW of the group $\mathrm{S} 1$ and $\mathrm{N}$ showed significant differences $(\mathrm{P}=0.035)$. The BW influences the dosage of administered drugs, which can influence the data of the present study including the time to recovery of TOF ratio, MBP, HR and PONV score. However, the comparison between group $\mathrm{S} 1$ and $\mathrm{N}$ are less important than the comparison between SN and S2; S2 and S1. The faster recovery and lower incidence of the systemic muscarinic side effect using sugammadex compared to neostigmine has been shown in previous studies $[1-5,13,17]$. Secondly, neostigmine also can cause hypersensitivity, albeit rare [30]. According to the New Drug Application of the US FDA at 2013 [30], there have been 5 reported anaphylaxis or hypersensitivity cases related to the use of neostigmine. Thirdly, the opportunity cost for the operating theater in Korea was not evaluated. The referred opportunity cost of the present study was estimated according to circumstances in the United Kingdom (UK) [13]. The opportunity cost of the operating theater include factors such as the cost of the anesthetic management, personnel expenses for surgery teams, and average profit of operating theater per time. The data regarding the opportunity cost for the operating theater in Korea could not be found and, thus, the investigators referenced data from the UK. Since health care in the UK is operated by the National Health Service in a manner similar to the National Health Insurance Service in Korea, the referred opportunity cost may be similar to 
that of Korea.

In conclusion, for the reversal of rocuronium induced moderate neuromuscular blockade, the combined use of sugammadex and neostigmine may be helpful to decrease the recovery time and can reduce the dose requirement of sugammadex. The clinical anesthesiologist, however, must consider the increased incidence of systemic muscarinic side effects when using sugam- madex combined with neostigmine.

\section{Acknowledgments}

This work was supported by the 2011 Inje University research grant.

\section{References}

1. Srivastava A, Hunter JM. Reversal of neuromuscular block. Br J Anaesth 2009; 103: 115-29.

2. Nicholson WT, Sprung J, Jankowski CJ. Sugammadex: a novel agent for the reversal of neuromuscular blockade. Pharmacotherapy 2007; 27: 1181-8.

3. Bom A, Hope F, Rutherford S, Thomson K. Preclinical pharmacology of sugammadex. J Crit Care 2009; 24: 29-35.

4. Mirakhur RK. Sugammadex in clinical practice. Anaesthesia 2009; 64 Suppl 1: 45-54.

5. Kopman AF. Neostigmine versus sugammadex: which, when, and how much? Anesthesiology 2010; 113: 1010-1.

6. Lee S. Sugammadex: a turning point in our practice. Korean J Anesthesiol 2013; 65: 493-4.

7. Park JY. Benefits and risks of sugammadex. Korean J Anesthesiol 2015; 68: 1-2.

8. Tsur A, Kalansky A. Hypersensitivity associated with sugammadex administration: a systematic review. Anaesthesia 2014; 69: 1251-7.

9. Cammu G, De Kam PJ, Demeyer I, Decoopman M, Peeters PA, Smeets JM, et al. Safety and tolerability of single intravenous doses of sugammadex administered simultaneously with rocuronium or vecuronium in healthy volunteers. Br J Anaesth 2008; $100: 373-9$.

10. Peeters PA, van den Heuvel MW, van Heumen E, Passier PC, Smeets JM, van Iersel T, et al. Safety, tolerability and pharmacokinetics of sugammadex using single high doses (up to $96 \mathrm{mg} / \mathrm{kg}$ ) in healthy adult subjects: a randomized, double-blind, crossover, placebo-controlled, single-centre study. Clin Drug Investig 2010; 30: 867-74.

11. Rex C, Bergner UA, Pühringer FK. Sugammadex: a selective relaxant-binding agent providing rapid reversal. Curr Opin Anaesthesiol 2010; 23: 461-5.

12. Godai K, Hasegawa-Moriyama M, Kuniyoshi T, Kakoi T, Ikoma K, Isowaki S, et al. Three cases of suspected sugammadex-induced hypersensitivity reactions. Br J Anaesth 2012; 109: 216-8.

13. Paton F, Paulden M, Chambers D, Heirs M, Duffy S, Hunter JM, et al. Sugammadex compared with neostigmine/glycopyrrolate for routine reversal of neuromuscular block: a systematic review and economic evaluation. Br J Anaesth 2010; 105: 558-67.

14. Kakinuma A, Nagatani H, Yasuda A, Yoshimura T, Sawai J, Nakata Y. Combined use of sugammadex and neostigmine for the reversal of rocuronium-induced profound neuromuscular blockade. J Anesthe Clinic Res 2013; 4: 7.

15. Eriksson LI. Evidence-based practice and neuromuscular monitoring: it’s time for routine quantitative assessment. Anesthesiology 2003; 98: $1037-9$.

16. Viby-Mogensen J, Jensen NH, Engbaek J, Ording H, Skovgaard LT, Chraemmer-Jørgensen B. Tactile and visual evaluation of the response to train-of-four nerve stimulation. Anesthesiology 1985; 63: 440-3.

17. Geldner G, Niskanen M, Laurila P, Mizikov V, Hübler M, Beck G, et al. A randomised controlled trial comparing sugammadex and neostigmine at different depths of neuromuscular blockade in patients undergoing laparoscopic surgery. Anaesthesia 2012; 67: 991-8.

18. Sacan O, White PF, Tufanogullari B, Klein K. Sugammadex reversal of rocuronium-induced neuromuscular blockade: a comparison with neostigmine-glycopyrrolate and edrophonium-atropine. Anesth Analg 2007; 104: 569-74.

19. Ali HH, Utting JE, Gray TC. Quantitative assessment of residual antidepolarizing block. II. Br J Anaesth 1971; 43: 478-85.

20. Debaene B, Plaud B, Dilly MP, Donati F. Residual paralysis in the PACU after a single intubating dose of nondepolarizing muscle relaxant with an intermediate duration of action. Anesthesiology 2003; 98: 1042-8.

21. Pedersen T, Viby-Mogensen J, Ringsted C. Anaesthetic practice and postoperative pulmonary complications. Acta Anaesthesiol Scand 1992; 36: 812-8.

22. Berg H, Roed J, Viby-Mogensen J, Mortensen CR, Engbaek J, Skovgaard LT, et al. Residual neuromuscular block is a risk factor for postoperative pulmonary complications. A prospective, randomised, and blinded study of postoperative pulmonary complications after atracurium, vecuronium and pancuronium. Acta Anaesthesiol Scand 1997; 41: 1095-103.

23. Naguib M, Kopman AF, Ensor JE. Neuromuscular monitoring and postoperative residual curarisation: a meta-analysis. Br J Anaesth 2007; 98: 302-16.

24. Menéndez-Ozcoidi L, Ortiz-Gómez JR, Olaguibel-Ribero JM, Salvador-Bravo MJ. Allergy to low dose sugammadex. Anaesthesia 2011; 66: 217-9.

25. Asahi Y, Omichi S, Adachi S, Kagamiuchi H, Kotani J. Hypersensitivity reaction probably induced by sugammadex. Acta Anaesthesiol 
Taiwan 2012; 50: 183-4.

26. Blobner M, Eriksson LI, Scholz J, Motsch J, Della Rocca G, Prins ME. Reversal of rocuronium-induced neuromuscular blockade with sugammadex compared with neostigmine during sevoflurane anaesthesia: results of a randomised, controlled trial. Eur J Anaesthesiol 2010; 27: 874-81.

27. Pühringer FK, Gordon M, Demeyer I, Sparr HJ, Ingimarsson J, Klarin B, et al. Sugammadex rapidly reverses moderate rocuronium- or vecuronium-induced neuromuscular block during sevoflurane anaesthesia: a dose-response relationship. Br J Anaesth 2010; 105: 610-9.

28. Sorgenfrei IF, Norrild K, Larsen PB, Stensballe J, Ostergaard D, Prins ME, et al. Reversal of rocuronium-induced neuromuscular block by the selective relaxant binding agent sugammadex: a dose-finding and safety study. Anesthesiology 2006; 104: 667-74.

29. Hovorka J, Korttila K, Nelskylä K, Soikkeli A, Sarvela J, Paatero H, et al. Reversal of neuromuscular blockade with neostigmine has no effect on the incidence or severity of postoperative nausea and vomiting. Anesth Analg 1997; 85: 1359-61.

30. Simone A. N204-078 Neostigmine methylsulfate clinical PREA/BPCA. NDA 204078. U S FDA. 2013 Apr 26. Available from http://www. fda.gov/downloads/drugs/developmentapprovalprocess/developmentresources/ucm361414.pdf 